\title{
BMJ Open Overview of systematic reviews on strategies to improve treatment initiation, adherence to antiretroviral therapy and retention in care for people living with HIV: part 1
}

Lawrence Mbuagbaw (D) , ${ }^{1,2,3}$ Anisa Hajizadeh, ${ }^{1}$ Annie Wang, ${ }^{1}$ Dominik Mertz, ${ }^{1,4}$ Daeria O Lawson (D) ,1,5 Marek Smieja, ${ }^{1,4}$ Anita C Benoit, ${ }^{6,7}$ Elizabeth Alvarez (D) ,1,8 Lisa Puchalski Ritchie, ${ }^{9,10,11}$ Beth Rachlis, ${ }^{12}$ Carmen Logie, ${ }^{6,13}$ Winston Husbands, ${ }^{14}$ Shari Margolese, ${ }^{15}$ Babalwa Zani, ${ }^{16}$ Lehana Thabane $e^{1,2,17,18,19}$

To cite: Mbuagbaw $L$, Hajizadeh A, Wang A, et al. Overview of systematic reviews on strategies to improve treatment initiation, adherence to antiretroviral therapy and retention in care for people living with HIV: part 1. BMJ Open 2020;10:e034793. doi:10.1136/ bmjopen-2019-034793

- Prepublication history for this paper is available online. To view these files, please visit the journal online (http://dx.doi. org/10.1136/bmjopen-2019034793).

Received 05 0ctober 2019 Revised 01 July 2020 Accepted 07 August 2020
Check for updates

(C) Author(s) (or their employer(s)) 2020. Re-use permitted under CC BY-NC. No commercial re-use. See rights and permissions. Published by BMJ.

For numbered affiliations see end of article.

Correspondence to Dr Lawrence Mbuagbaw; mbuagblc@mcmaster.ca

\section{ABSTRACT}

Objectives We sought to map the evidence and identify interventions that increase initiation of antiretroviral therapy, adherence to antiretroviral therapy and retention in care for people living with HIV at high risk for poor engagement in care.

Methods We conducted an overview of systematic reviews and sought for evidence on vulnerable populations (men who have sex with men (MSM), African, Caribbean and Black (ACB) people, sex workers (SWs), people who inject drugs (PWID) and indigenous people). We searched PubMed, Excerpta Medica dataBASE, Cumulative Index to Nursing and Allied Health Literature, PsycINFO, Web of Science and the Cochrane Library in November 2018. We screened, extracted data and assessed methodological quality in duplicate and present a narrative synthesis.

Results We identified 2420 records of which only 98 systematic reviews were eligible. Overall, 65/98 (66.3\%) were at low risk of bias. Systematic reviews focused on ACB (66/98; 67.3\%), MSM (32/98; 32.7\%), PWID (6/98; 6.1\%), SWs and prisoners (both 4/98; 4.1\%). Interventions were: mixed (37/98; 37.8\%), digital (22/98; $22.4 \%)$, behavioural or educational $(9 / 98 ; 9.2 \%)$, peer or community based (8/98; 8.2\%), health system (7/98; $7.1 \%)$, medication modification $(6 / 98 ; 6.1 \%)$, economic (4/98; $4.1 \%)$, pharmacy based $(3 / 98 ; 3.1 \%)$ or taskshifting $(2 / 98 ; 2.0 \%)$. Most of the reviews concluded that the interventions effective $(69 / 98 ; 70.4 \%), 17.3 \%$ (17/98) were neutral or were indeterminate $12.2 \%(12 / 98)$. Knowledge gaps were the types of participants included in primary studies (vulnerable populations not included), poor research quality of primary studies and poorly tailored interventions (not designed for vulnerable populations). Digital, mixed and peer/community-based interventions were reported to be effective across the continuum of care.

Conclusions Interventions along the care cascade are mostly focused on adherence and do not sufficiently address all vulnerable populations.

\section{Strengths and limitations of this study}

- To the best of our knowledge, this is the first overview to address the whole cascade of care for people living with HIV.

- Our categorisation of systematic reviews by intervention type and the intervention's success will permit decision makers to easily identify the interventions that are likely to work for their specific context.

- We categorised systematic reviews to facilitate data synthesis, however we acknowledge that certain interventions may fit into multiple categories.

- Among mixed interventions, it was challenging to determine the role of the individual intervention types on the overall effect.

- This report at the systematic review level does not cover all aspects of the interventions, which can only be retrieved from individual trials.

\section{BACKGROUND}

Despite advances in diagnosis and management of HIV infection, many people living with HIV still do not have optimal outcomes. In 2014, the Joint United Nations Programme on HIV/AIDS (UNAIDS) set the 90-90-90 target for $2020 .{ }^{1}$ If this target is met, $90 \%$ of people living with HIV will know their HIV status; $90 \%$ of all people diagnosed with HIV will be receiving antiretroviral therapy (ART) and $90 \%$ of all people on ART will be virally suppressed. ${ }^{1}$ These targets are contingent on engagement in the cascade of care that includes access to testing, timely diagnosis, access to and initiation of treatment, adherence to treatment and retention in care. Despite national efforts, very few countries have actually met these targets. ${ }^{2}$ The UK 
has met these targets ${ }^{3}$ and Botswana and Australia are on track. ${ }^{4}$ Canada is also on track to meet these targets, with $87 \%$ of people with HIV diagnosed, $82 \%$ on treatment and $93 \%$ virally suppressed. ${ }^{5}$ For countries to meet these targets, there must be policies in place to support programmes that deliver interventions across the entire cascade of care. As such, there must be awareness, reductions in stigma and incentives that promote testing alongside strategies to enhance treatment initiation, adherence and retention in care. ${ }^{6}$ Consistent access to ART and highquality data should be collected so that advances towards the targets can be measured appropriately. ${ }^{6}$

If all these conditions are met and countries meet these targets, there are still concerns that the targets may be met at a national level but not in certain subpopulations. ${ }^{78}$ The literature suggests that vulnerable populations such as men who have sex with men (MSM), sex workers (SWs), people who inject drugs (PWID), people with precarious migration status and ethno-racial minorities have a higher disease burden, worse engagement in care and are less likely to achieve viral suppression. ${ }^{9-14}$ MSM and SWs all over the world are 19 and 13.5 times more likely to be living with HIV. ${ }^{78}$ In Canada, inequities in social and structural determinants such as injection drug use, ethno-racial background, age, housing, sex work and gender affect engagement in care. ${ }^{11-15}$

The literature is rife with interventions aimed at improving different aspects of the care cascade. However, the challenges countries face in achieving the UNAIDS targets suggest that the interventions may not be effective, may not be properly translated into practice or may not be tailored (designed to have optimal impact on groups with different sociodemographic or risk characteristics that could influence the effect of the intervention) to the relevant populations. Therefore, due consideration of the settings in which interventions are tested, their target populations, complexity and applicability in the real world are important considerations for scale up. ${ }^{1617}$ These limitations in the quality and quantity of evidence were identified in the International Association of Physicians in AIDS Care guideline document. ${ }^{18}$

While HIV is still a leading cause of disease burden in sub-Saharan Africa, ${ }^{19}$ vulnerable populations in highincome countries may experience a comparable disease burden if they are not recognised as a priority. ${ }^{20}$ As countries strive to meet the 90-90-90 target, it is becoming apparent that due to the disparities in outcomes across jurisdictions and populations, better targeted approaches are required to improve engagement in care. ${ }^{21}$ Ontario is the most populous province of Canada and home to $42 \%$ of Canada's 71000 people living with HIV. Due to individual, social and structural factors, it is estimated that approximately $20 \%$ of these people living with HIV in Canada have discontinuous care. ${ }^{11}$ In Ontario, $80 \%-87 \%$ of people living with HIV are in care, $70 \%-82 \%$ are on ART and $67 \%-81 \%$ are virally suppressed..$^{22}$ This overview of systematic reviews will inform policy, practice and research in Ontario and other high-income settings especially with regards to engagement in HIV care for vulnerable populations. We sought to map the available evidence on strategies that improve engagement in the HIV care cascade (initiation of treatment, adherence to medication and retention in care) for priority populations as well as to identify knowledge gaps (see figure 1).

This overview is the first part of our report and includes a high-level summary of the findings from systematic reviews, with no distinction by country. We provide a map of the evidence here, and the second part will summarise the findings from the randomised trials included in the systematic reviews.

\section{METHODS}

We conducted an overview of systematic reviews using standard Cochrane methods. ${ }^{23}$ The protocol for this overview has been published elsewhere. ${ }^{24}$ Key features of our methods are outlined below.

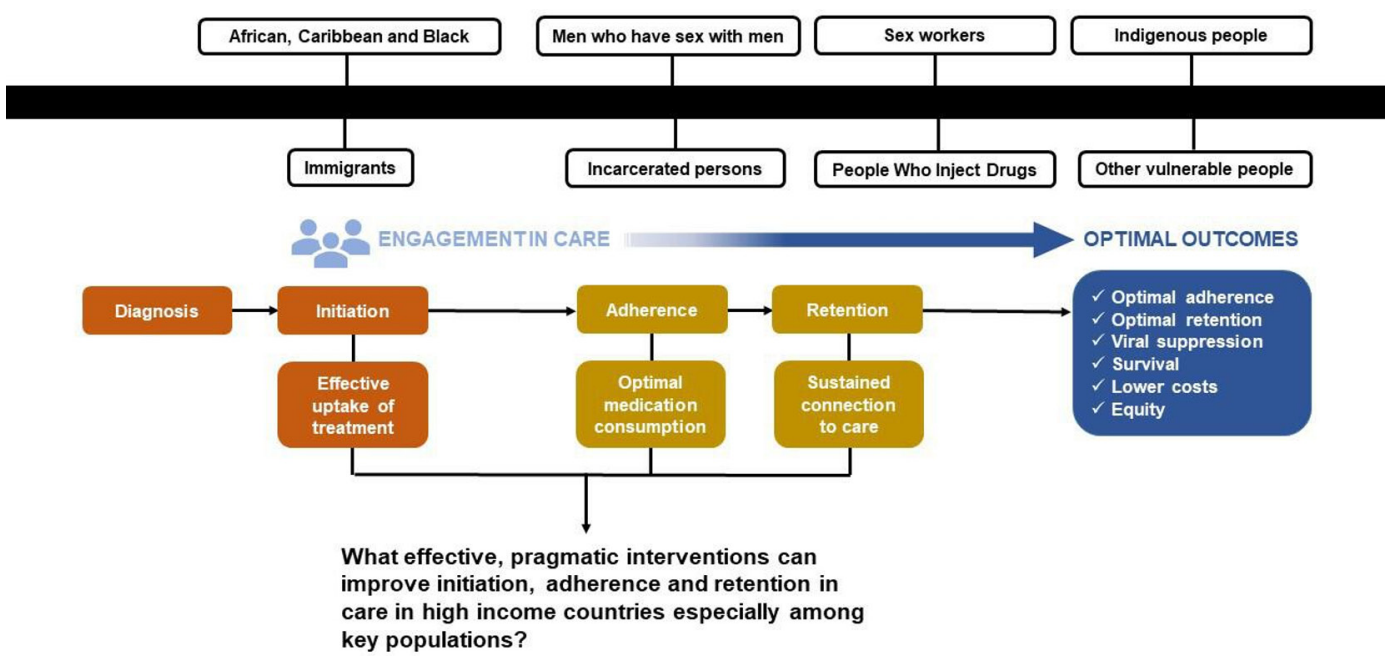

Figure 1 Outline of the HIV care cascade. 


\section{Patient and public involvement}

Our research question was formulated and refined based on input from the Ontario HIV Treatment Network (OHTN), a non-profit network, as part of their strategy to close gaps in the cascade of care for key populations. The investigators include patients, clinicians, researchers and representatives of AIDS Service Organisations/ Community-Based Organisations. Decision makers and representatives from the Ministry of Health and LongTerm Care of Ontario were also consulted.

\section{Criteria for considering reviews for inclusion}

We included any systematic reviews with at least one study with a randomised comparison of an intervention designed to improve initiation of ART, adherence to ART and/or retention in care among people living with HIV. We excluded abstracts, non-systematic reviews and other overviews. All comparators (eg, attention control, usual care, another intervention) were eligible for inclusion. We had no restriction on the location of the studies or the ages of the participants.

\section{Search methods for identification of reviews}

We conducted an exhaustive and comprehensive search of the following databases: PubMed, Excerpta Medica dataBASE, Cumulative Index to Nursing and Allied Health Literature, PsycINFO, Web of Science and the Cochrane Library; from 1995 (when combination ART was introduced) to 13 November 2018. The search strategy was reviewed by a librarian at Health Sciences Centre Library at McMaster University. The full search strategy is reported as a supplemental file (online supplemental appendix 1).

We also searched the websites of the WHO, UNAIDS, National Institute for Health and Care Excellence and the systematic review database housed at the OHTN: Synthesised HIV/AIDS Research Evidence (http://www. hivevidence.ca/frmSearch.aspx).

Finally, we looked for additional systematic reviews in the bibliographies of the included reviews.

\section{Screening}

The results of our search were collated in EndNote reference manager. ${ }^{25}$ Duplicates were removed and all the references were uploaded unto DistillerSR (Evidence Partners, Ottawa, Canada). We screened the retrieved citations in duplicate with reviewer pairs (BZ, AW, AH) first by examining the titles and abstracts and second by examining the full texts. Systematic reviews that met our inclusion criteria were processed and data were extracted.

\section{Data items}

From the systematic reviews, we extracted standard bibliometric data (author, year), number of included primary studies and their designs, target populations, types of interventions, outcomes of interest, key findings and knowledge gaps. Data were extracted in duplicate by reviewers working in pairs $(\mathrm{BZ}, \mathrm{AW}, \mathrm{AH})$.
Assessment of methodological quality of included reviews

We appraised the methodological quality of the included reviews using the risk of bias in systematic reviews tool. ${ }^{26}$ This tool allows reviewers to assess the relevance of the question, identify concerns with the review process and make a judgement on risk of bias (high, low, unclear). Risk of bias was appraised in duplicate by pairs of reviewers (BZ, AW, AH).

Discrepancies and disagreements in screening, data extraction and risk of bias were resolved by consensus or by adjudication by a third reviewer (LM).

\section{Data synthesis}

The extracted data were described narratively. Systematic reviews were organised according to the portion of the care cascade they addressed (ie, initiation, adherence, retention) and the intervention types: behavioural or educational, digital, mixed, economic, health system, medication modification, peer or community based, pharmacy based or task-shifting. These categories were developed post-hoc to facilitate data synthesis. The types of interventions included in each category are outlined in table 1.

Conclusion statements were categorised according to a previously used framework: positive (evidence of effectiveness); neutral (no evidence of effectiveness or no opinion); negative (authors advise against the use of intervention); indeterminate (insufficient evidence or more research is required). ${ }^{27}$ Knowledge gaps were operationalised according to guidance on how to report research recommendations by identifying the state of the evidence, participants, interventions, comparisons and outcomes for which further research is needed. ${ }^{28} \mathrm{We}$ also discuss our findings within the scope of the Health Systems Arrangement Framework. ${ }^{29}$ In this framework, interventions may be organised to inform different parts of the decision-making process, and interventions can be related to governance, financial or delivery arrangements. ${ }^{29}$ Intervention effects are summarised according to the vulnerable population they were tested with, intervention target (initiation, adherence, retention) and risk of bias. Interventions reported in systematic with positive recommendations are highlighted. Our findings are reported according to the Preferred Reporting Items for Systematic Reviews and Meta-Analyses (PRISMA) statement. $^{30}$

\section{RESULTS}

\section{Literature search}

Our search identified 2420 records from electronic databases and 76 from other sources. After removal of duplicates, 1505 titles and abstracts were screened, of which 1006 were considered ineligible and excluded. We further screened 499 full-text articles and included 98. Agreement on the screening of full-text articles was high (Kappa $=0.79)$. The screening process is outlined in a PRISMA flow diagram (figure 2). ${ }^{30} \mathrm{~A}$ full list of excluded 
Table 1 Categorisation of intervention types in the systematic reviews

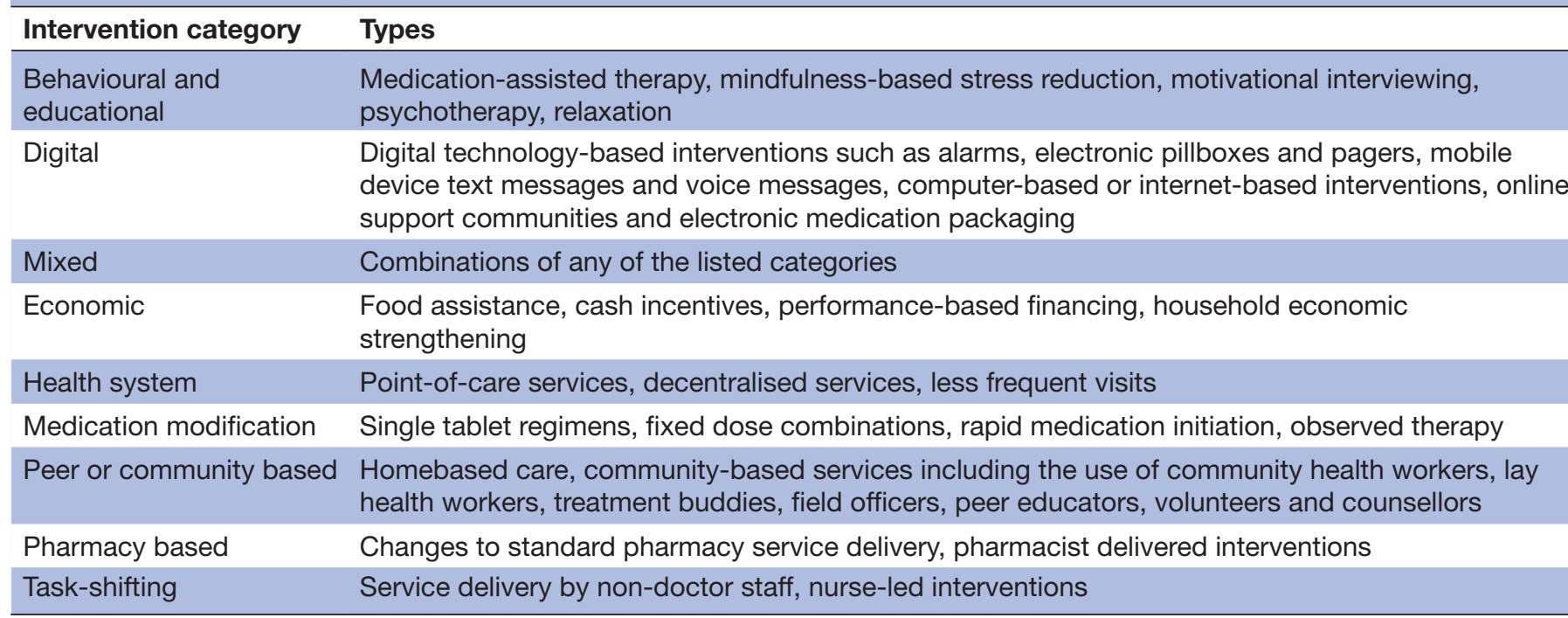

systematic reviews is provided as a supplemental file (online supplemental appendix 2).

\section{Description of included reviews}

The 98 included systematic reviews were published between 2006 and 2018 $8^{31-128}$ and reported on interventions to improve initiation of care $(n=18), 32415458616465$ 707578818492100109113123126 adherence to ART $(\mathrm{n}=82)^{31-36}$ 3839 41-53 5557596062 65-68 71-77 79-108 110-112 114-116 118-122 124125 127128 and retention in care $(\mathrm{n}=39) .^{32} 374041525658-60$ 63-66 68-70 75-78 8184868889 91-939596100101 105 113 115-117 126128 Thirty-one (31) reviews reported two or more aspects of the cascade. $^{32} 4152$ 58-60 64-66 70 75-78 818486888991929596100101105113 115116126128 They included a median (quartile 1; quartile 3 (Q1; Q3)) of $19(11 ; 28)$ primary studies and $8(4 ; 13)$ randomised trials.

With regards to vulnerable populations, $32.7 \%(32 / 98)$ included primary studies involving MSM,, $313340-4245474851$ 525965707380818587899296 98-100 104-106 108110113114119

(66/96) involving African, Caribbean or Black (ACB) people, ${ }^{31-34} 3637404345474850$ 52-54 56 58-61 63-66 7071 73-82 84-87 8990929395 101-104 106 108-110 112-120123125126128 25.5\% (25/98) focused on PWID, $394143444850-52606668707374858891929699100$

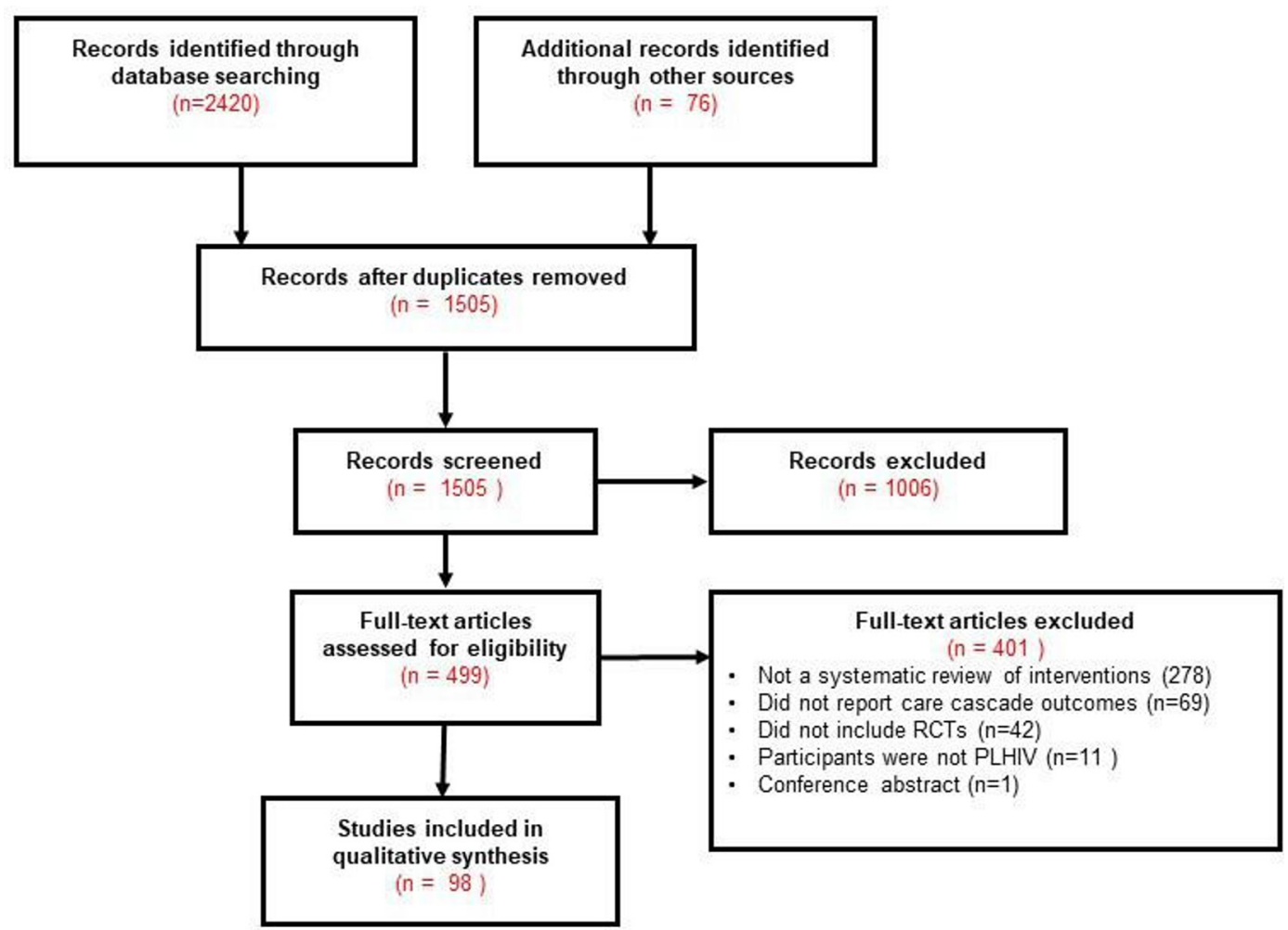

Figure 2 Systematic review flow diagram. PLHIV, people living with HIV; RCTs, randomised controlled trials. 
Table 2 Summary characteristics of included systematic reviews: $\mathrm{n}=98$

\begin{tabular}{|c|c|}
\hline Variable & Statistic \\
\hline Year: median (quartile 1; quartile 3) & $2015(2013 ; 2017)$ \\
\hline $\begin{array}{l}\text { Number of included primary studies: } \\
\text { median (quartile 1; quartile 3) }\end{array}$ & $29(11 ; 28)$ \\
\hline $\begin{array}{l}\text { Number of randomised trials: median } \\
\text { (quartile } 1 \text {; quartile } 3 \text { ) }\end{array}$ & $8(4 ; 13)$ \\
\hline \multicolumn{2}{|l|}{ Vulnerable populations included: $\mathrm{n}(\%)$} \\
\hline African, Caribbean or Black & $66(67.3)$ \\
\hline Men who have sex with men & $32(32.7)$ \\
\hline People who inject drugs & $25(25.5)$ \\
\hline Sex workers & $6(6.1)$ \\
\hline Immigrants & $4(4.1)$ \\
\hline Incarcerated persons & $4(4.1)$ \\
\hline \multicolumn{2}{|l|}{ Intervention categories: n (\%) } \\
\hline Mixed & $37(37.8)$ \\
\hline Digital & $22(22.4)$ \\
\hline Behavioural or educational & $9(9.2)$ \\
\hline Peer or community based & $8(8.2)$ \\
\hline Health system & $7(7.1)$ \\
\hline Medication modification & $6(6.1)$ \\
\hline Economic & $4(4.1)$ \\
\hline Pharmacy & $3(3.1)$ \\
\hline Task-shifting & $2(2.0)$ \\
\hline \multicolumn{2}{|l|}{ Care cascade outcomes: $n(\%)$ * } \\
\hline Adherence & $82(59.0)$ \\
\hline Retention & $39(28.1)$ \\
\hline Initiation & 18 (12.9) \\
\hline
\end{tabular}

${ }^{*}$ Not mutually exclusive.

$1051081161216.1 \%$ (6/98) involving SW, $41424852961004.1 \%$ (4/98) included data on immigrants 4282108126 and $4.1 \%$ (4/98) included data on incarcerated persons. 406091105 These characteristics are summarised in table 2. A full list of the 98 included systematic reviews is reported as a supplemental file (online supplemental appendix 3).

\section{Methodological quality of included reviews}

Most of the systematic reviews were judged to be a low risk of bias $(65(66.3 \%))$. Twenty $(20.4 \%)$ were judged to be at high risk of bias and $13(13.3 \%)$ were judged to be at unclear risk of bias. The most frequent concern was related to data collection and primary study appraisal (28.6\% at high risk of bias in this domain). The main concerns we identified were no risk of bias assessments conducted, missing primary study information and no evidence that data had been processed in duplicate. This was followed by the risk of bias in the identification and selection of primary studies $(19.4 \%$ at high risk of bias in this domain). The main limitations we identified were not searching grey literature, searching less than two databases, exclusion of non-English primary studies, no evidence that data were processed in duplicate and not reporting the search strategy. For the domain of study eligibility criteria $(15.3 \%$ at high risk of bias in this domain) the main concerns were: eligibility criteria not described in sufficient detail, ambiguous criteria and restrictions based on publication status and language. For the domain of synthesis and findings $(15.3 \%$ at high risk of bias in this domain) the main concerns were: heterogeneity was not assessed, choice of synthesis approach not justified and primary study biases not addressed (see figure 3 and online supplemental appendix 3).

\section{Effects of interventions}

Most systematic reviews gave positive recommendations for the interventions they examined $(69 / 70.4 \%)$. Seventeen $(17.3 \%)$ were neutral and $12(12.2 \%)$ were indeterminate. No systematic reviews recommended against any interventions. Positive findings from systematic reviews are outlined below. All our findings, positive, negative, neutral and indeterminate are summarised in a supplemental file (online supplemental appendix 3).

\section{Initiation}

Of the 18 systematic reviews that examined initiation of ART as an outcome, $11(61.1 \%)$ at low risk of bias reported that digital, ${ }^{41} 100$ mixed, ${ }^{32} 547584$ health system ${ }^{66} 78123$ and peer-based or community-based interventions ${ }^{65} 113$ improved initiation of ART. Two systematic reviews at high or unclear risk of bias reported that digital ${ }^{64}$ and mixed interventions improved initiation of ART. ${ }^{70}$

\section{Adherence}

Of the 82 systematic reviews that examined adherence to ART as an outcome, 25 (30.5\%) at low risk of bias reported that behavioural/educa-

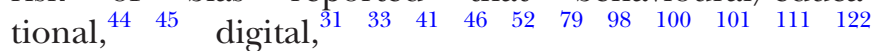
mixed, , 323643535762727475828491103105108112 health system, ${ }^{50}$ medication modification, ${ }^{49} \quad 59102$ peer/communitybased, $^{73} 96128$ pharmacy-based $^{86} 111$ and task-shifting interventions $^{77}$ improved adherence to ART. Eighteen $(18 / 21.9 \%)$ systematic reviews at high or unclear risk of bias reported that behavioural/educational, ${ }^{39} 104$ digital, ${ }^{42} 718590$ mixed, ${ }^{50808999114127}$ economic, ${ }^{5568116}$ medication modification, ${ }^{97}$ peer-based or community-based ${ }^{125}$ and task-shifting ${ }^{118}$ interventions improved adherence to ART.

\section{Retention}

Of the 39 systematic reviews that examined retention in care as an outcome, $21(53.8 \%)$ systematic reviews at low risk of bias reported that digital, ${ }^{4152100}$ mixed, ${ }^{326669758491105}$ economic, ${ }^{115}$ health system, ${ }^{66} 7895$ medication modification, ${ }^{59}$ peer/community-based ${ }^{6596113128}$ and task-shifting ${ }^{77}$ interventions improved adherence to HIV care. Seven $(7 / 17.9 \%)$ of systematic reviews at high or unclear risk of bias reported that behavioural/educational, ${ }^{37}$ digital, ${ }^{64}$ mixed, ${ }^{70} 89$ economics, ${ }^{116}$ health system ${ }^{40}$ and peer-based 
Risk of bias in included Reviews

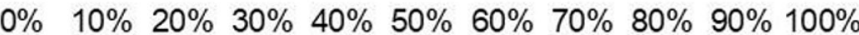

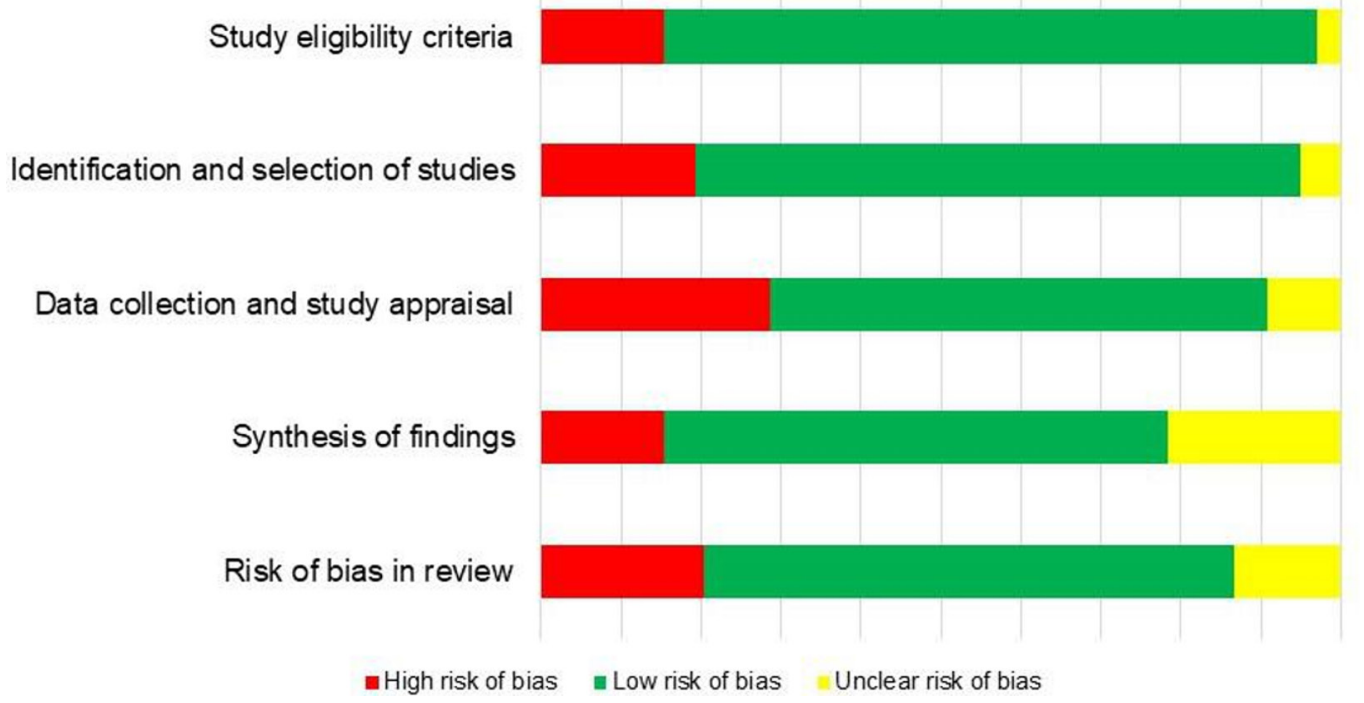

Figure 3 Risk of bias summary.

or community-based interventions ${ }^{56}$ improved retention in care.

Figure 4 is a display of the available evidence, showing intervention type by HIV care cascade target (panel a), intervention type by authors' conclusions (panel b) and key population by HIV care cascade target (panel c).

\section{Knowledge gaps}

The most frequent knowledge gap identified in 22 $(22.4 \%)$ systematic reviews was with regards to the population studied, where further investigation with vulnerable and marginalised groups such as children, youth, MSM, pregnant and breastfeeding women, individuals in low-income settings, individuals with concurrent mental health issues and older adults is required. The authors also raised concerns about the primary study designs $(n=22 / 22.4 \%)$ and primarily called for more robust, innovative, rigorous and high-quality designs, including experimental designs, (pragmatic) randomised trials, longer follow-up times, mixed methods approaches and primary studies with larger sample sizes. The nature of the intervention was also identified as a knowledge gap $(22 / 22.4 \%)$. The authors found that interventions were not sufficiently tailored to high-risk populations, lowincome settings, were too costly or did not cover the entire cascade of care. They further suggested that novel interventions be investigated and older intervention be combined to assess synergistic effects. Only two $(2.0 \%)$ systematic reviews raised concerns about the nature of the

\section{Evidence maps of HIV care cascade interventions}

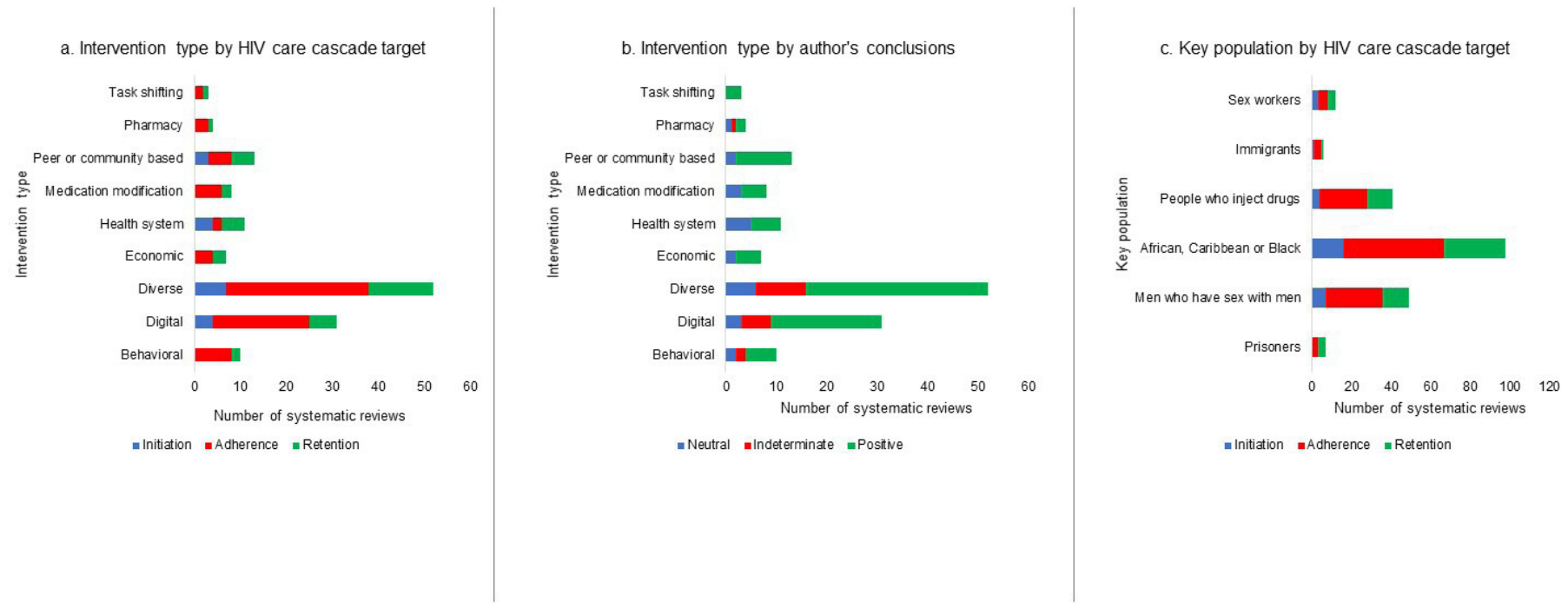

Figure 4 Evidence maps of HIV care cascade interventions. 
outcomes used. ${ }^{72}{ }^{83}$ They called for universal definitions for adherence and the use of more humanistic, economic and patient-important outcomes.

\section{DISCUSSION}

We conducted an exhaustive and comprehensive search for systematic reviews focused on examining interventions that enhance ART initiation, ART adherence and retention among people living with HIV. We included 98 systematic reviews. Most of the systematic reviews we identified focused on adherence-enhancing interventions and investigated a mixed range of intervention categories. For the most part, the authors of the included systematic reviews found that the interventions were effective $(70.4 \%)$. Digital, mixed and peer/community-based interventions were the only three categories of interventions that were reported to be effective across the whole continuum of care. The main knowledge gaps identified in most systematic reviews was a lack of focus on the populations that would benefit the most $(22.4 \%)$, poor quality of the primary studies $(22.4 \%)$ and nature of the interventions $(22.4 \%)$.

We further examined to what extent health systems arrangements were met by this body of evidence. Most systematic reviews focused on the delivery of interventions (task-shifting, homebased care, pharmacy-based interventions) but none addressed governance of HIV care and very few addressed financial components (food assistance, cash incentives, performance-based financing, household economic strengthening) that may support or hinder access to HIV care and treatment. ${ }^{5568115116}$ This may be an important limitation in how research is designed, without adequate consideration of the facets of a health system that could influence outcomes.

Most of the systematic reviews were at low risk of bias $(66.3 \%) .{ }^{26}$ However, there were some concerns, notably with issues related to reporting of details in review conduct which indicated high or unclear risk of bias. We recognise that journal word count limitations may prevent authors from reporting all the relevant details, but appendices could be used to provide additional details. Risk of bias from these systematic reviews should be interpreted in context and may differ from the risk of bias in the primary studies included.

To the best of our knowledge, there is no other overview of systematic reviews investigating the cascade of HIV care, but our findings confirm previous research indicating a paucity of research on vulnerable populations ${ }^{129}$ and challenges with scaling-up interventions. ${ }^{130}$

The disproportionate study of adherence might be due to its perceived importance as a cornerstone of care or the relative ease of designing adherence studies. Prior to recent recommendations to treat all diagnosed people, initiation of treatment was seldom a priority. ${ }^{131}$ Likewise, retention in care is an outcome that requires substantially longer follow-up to generate meaningful results. ${ }^{11} 132$ In order for countries to meet the 90-90-90 target, the cascade of care must be viewed as continuum, not just for practice, but also for research, such that interventions that strengthen the entire cascade be scaled up.

Even though only disparate definitions of adherence to ART were identified by the authors of some systematic reviews, we believe such diversity may exist with retention in care, as other studies have noted that there is no gold standard for what constitutes adequate retention. ${ }^{133}$ Future work on the trials included in the systematic reviews will permit us to describe the breadth of definitions used for both adherence and retention. Standardised definitions are important for jurisdictions to be able to measure changes over time and make cross jurisdictional comparisons. Standardised definitions will also help systematic reviewers to synthesise research.

\section{Strengths and limitations}

We acknowledge the following limitations. Despite our attempt to group the interventions into categories, we recognise that certain interventions may fit into more than one category. For example, tasking-shifting and pharmacy-based interventions can be viewed as health system or community-based interventions. Second, for the group of systematic reviews that investigated mixed interventions, it is challenging to determine the role of the individual intervention types on the overall effect. This group could contain interventions from any category and therefore it is not surprising that the systematic reviews that included mixed interventions often found a significant effect. Within each systematic review, the diversity of study designs, populations and primary studies from various income levels precluded in-depth investigation of how these issues may have affected intervention effectiveness at the systematic review level. No distinction was made between ACB populations in their respective countries versus ACB populations in high-income countries where the vulnerability is different. Further ongoing work on the trials included in these systematic reviews will highlight the features of interventions in ACB populations. Some primary studies are included in more than one systematic review. This highlights the need for a primary study-level analysis. Also, we reiterate that the statements on effectiveness are drawn from the concluding statements from the included systematic reviews and should therefore be interpreted with caution. Finally, despite our efforts to conduct a comprehensive and exhaustive search, it is possible that some systematic reviews were missed if they were indexed with terms we did not include in our strategy.

This work has many strengths. In addition to using a predefined protocol, we conducted a comprehensive search, assessed risk of bias, investigated the availability of data on vulnerable populations and categorised the systematic reviews by type of intervention and success of the intervention. This approach would permit decision makers and other end users to identify intervention type that are likely to work for specific populations at each 
point of the care cascade. However, a trial-level analyses is required to enrich these findings.

\section{CONCLUSION}

We found limited research on vulnerable populations and uneven focus on the three aspects of the care cascade. In order to identify the most effective and pragmatic interventions for vulnerable populations in high-income settings, a study-level analysis is required. The diversity of the interventions examined and the populations studied indicate the need for network meta-analyses in this field, some of which have already been published. ${ }^{90}$ The lack of systematic reviews that generate evidence on governance is indicative of how removed many research endeavours are from policy-making. Monitoring and evaluation also need to be considered within systems to support up-todate collection of data on detection, initiation, adherence and retention in care.

\section{Differences between protocol and review}

There are a few differences between this report and the protocol. First, after additional consultation with stakeholders, we included interventions targeting initiation of ART. Given the amount of data, we decided to report our findings on two levels, the systematic review level and the primary study level. Only the systematic review level is reported here, and therefore in-depth analyses of the settings (high vs low income) of the primary studies and the levels of pragmatism, and certainty of the evidence are reserved for a second paper.

\section{Author affiliations}

${ }^{1}$ Department of Health Research Methods, Evidence and Impact, McMaster University, Hamilton, Ontario, Canada

${ }^{2}$ Biostatistics Unit, Father Sean 0'Sullivan Research Centre, St Joseph's Healthcare, Hamilton, Ontario, Canada

${ }^{3}$ Centre for the Develoment of Best Practices in Health, Yaounde Central Hospital, Yaounde, Cameroon

${ }^{4}$ Department of Medicine, McMaster University, Hamilton, Ontario, Canada

${ }^{5}$ Division of Rheumatology, Toronto Western Hospital, Toronto, Ontario, Canada

${ }^{6}$ Women's College Research Institute, Toronto, Ontario, Canada

${ }^{7}$ Dalla Lana School of Public Health, University of Toronto, Toronto, Ontario, Canada

${ }^{8}$ Centre for Health Economics and Policy Analysis (CHEPA), McMaster University, Hamilton, Ontario, Canada

${ }^{9}$ Department of Medicine, University of Toronto, Toronto, Ontario, Canada

${ }^{10}$ Department of Emergency Medicine, University Health Network, Toronto, Ontario, Canada

${ }^{11} \mathrm{Li}$ Ka Shing Knowledge Institute, St Michael's Hospital, Toronto, Ontario, Canada

${ }^{12}$ Division of Clinical Public Health, Dalla Lana School of Toronto, University of Toronto, Toronto, Ontario, Canada

${ }^{13}$ Factor-Inwentash Faculty of Social Work, University of Toronto, Toronto, Ontario, Canada

${ }^{14}$ Ontario HIV Treatment Network, Toronto, Ontario, Canada

${ }^{15}$ Canadian HIV Trials Network Community Advisory Committee, Vancouver, British Columbia, Canada

${ }^{16}$ Knowledge Translation Unit, University of Cape Town Lung Institute, Rondebosch, Western Cape, South Africa

${ }^{17}$ Pediatrics and Anesthesia, McMaster University, Hamilton, Ontario, Canada

${ }^{18}$ Centre for Evaluation of Medicine, St Joseph's Healthcare Hamilton, Hamilton, Ontario, Canada

${ }^{19}$ Population Health Research Institute, Hamilton Health Sciences, Hamilton, Ontario, Canada
Contributors LM developed the first draft of the manuscript. AH, AW, LM and BZ extracted data and created tables. EA, DOL, BR, MS, DM, LPR, CL, SM, ACB, WH, AH, $A W, B Z$ and $L T$ revised several versions of the manuscript and approved the final version. $L M$ is the guarantor of the manuscript.

Funding This work was supported by The Ontario HIV Treatment Network (OHTN) grant number EFP-1096-Junior Inv.

Competing interests None declared.

Patient consent for publication Not required.

Provenance and peer review Not commissioned; externally peer reviewed.

Data availability statement All data relevant to the study are included in the article or uploaded as supplemental information.

Open access This is an open access article distributed in accordance with the Creative Commons Attribution Non Commercial (CC BY-NC 4.0) license, which permits others to distribute, remix, adapt, build upon this work non-commercially, and license their derivative works on different terms, provided the original work is properly cited, appropriate credit is given, any changes made indicated, and the use is non-commercial. See: http://creativecommons.org/licenses/by-nc/4.0/.

\section{ORCID iDs}

Lawrence Mbuagbaw http://orcid.org/0000-0001-5855-5461

Daeria 0 Lawson http://orcid.org/0000-0002-6487-3367

Elizabeth Alvarez http://orcid.org/0000-0003-2333-0144

\section{REFERENCES}

1 UNAIDS. 90-90-90: an ambitious treatment target to help end the AIDS epidemic. secondary 90-90-90: an ambitious treatment target to help end the AIDS epidemic, 2014. Available: https://www. unaids.org/sites/default/files/media_asset/90-90-90_en.pdf

2 Levi J, Raymond A, Pozniak A, et al. Can the UNAIDS 90-90-90 target be achieved? A systematic analysis of national HIV treatment cascades. BMJ Glob Health 2016;1:e000010.

3 Kirby T. The UK reaches UNAIDS 90-90-90 targets. Lancet 2018;392:2427.

4 Marukutira T, Stoové M, Lockman S, et al. A tale of two countries: progress towards UNAIDS 90-90-90 targets in Botswana and Australia. J Int AIDS Soc 2018;21:e25090.

5 Canada Go. Summary: measuring Canada's progress on the 90-9090 HIV targets. secondary summary: measuring Canada's progress on the 90-90-90 HIV targets, 2017. Available: https://www.canada. $\mathrm{ca} / \mathrm{en} /$ public-health/services/publications/diseases-conditions/ summary-measuring-canada-progress-90-90-90-hiv-targets.html

6 Bain LE, Nkoke C, Noubiap JJN. UNAIDS 90-90-90 targets to end the AIDS epidemic by 2020 are not realistic: comment on "Can the UNAIDS 90-90-90 target be achieved? A systematic analysis of national HIV treatment cascades". BMJ Glob Health 2017;2:e000227-27.

7 Baral S, Sifakis F, Cleghorn F, et al. Elevated risk for HIV infection among men who have sex with men in low- and middle-income countries 2000-2006: a systematic review. PLoS Med 2007;4:e339.

8 Baral S, Beyrer C, Muessig K, et al. Burden of HIV among female sex workers in low-income and middle-income countries: a systematic review and meta-analysis. Lancet Infect Dis 2012;12:538-49.

9 Cescon AM, Cooper C, Chan K, et al. Factors associated with virological suppression among HIV-positive individuals on highly active antiretroviral therapy in a multi-site Canadian cohort. HIV Med 2011;12:352-60.

10 CATIE. The epidemiology of HIV in Canada. secondary the epidemiology of HIV in Canada, 2017. Available: http://www.catie. $\mathrm{ca} / \mathrm{en} / \mathrm{fact}$-sheets/epidemiology/epidemiology-hiv-canada

11 Rachlis B, Burchell AN, Gardner S, et al. Social determinants of health and retention in HIV care in a clinical cohort in Ontario, Canada. AIDS Care 2017;29:828-37.

12 Joseph B, Kerr T, Puskas CM, et al. Factors linked to transitions in adherence to antiretroviral therapy among HIV-infected illicit drug users in a Canadian setting. AIDS Care 2015;27:1128-36.

13 Kerr T, Palepu A, Barness G, et al. Psychosocial determinants of adherence to highly active antiretroviral therapy among injection drug users in Vancouver. Antivir Ther 2004;9:407-14.

14 Lourenço L, Nohpal A, Shopin D, et al. Non-Hiv-Related health care utilization, demographic, clinical and laboratory factors associated with time to initial retention in HIV care among HIV-positive individuals linked to HIV care. HIV Med 2016;17:269-79. 
15 Tapp C, Milloy M-J, Kerr T, et al. Female gender predicts lower access and adherence to antiretroviral therapy in a setting of free healthcare. BMC Infect Dis 2011;11:86-7.

16 Barker PM, Reid A, Schall MW. A framework for scaling up health interventions: lessons from large-scale improvement initiatives in Africa. Implementation Sci 2015;11.

17 Willis CD, Riley BL, Stockton L, et al. Scaling up complex interventions: insights from a realist synthesis. Health Res Policy Syst 2016;14:88.

18 Thompson MA, Mugavero MJ, Amico KR, et al. Guidelines for improving entry into and retention in care and antiretroviral adherence for persons with HIV: evidence-based recommendations from an international association of physicians in AIDS care panel. Ann Intern Med 2012;156:817-33.

19 Dwyer-Lindgren L, Cork MA, Sligar A, et al. Mapping HIV prevalence in sub-Saharan Africa between 2000 and 2017. Nature 2019;570:189-93.

20 Rights of vulnerable people and the future of HIV/AIDS. Lancet Infect Dis 2010;10:67.

21 Porter K, Gourlay A, Attawell K, et al. Substantial heterogeneity in progress toward reaching the 90-90-90 HIV target in the who European region. J Acquir Immune Defic Syndr 2018;79:28-37.

22 OHESI. Hiv care cascade in Ontario: linkage to care, in care, on antiretroviral treatment, and virally suppressed, 2015. secondary HIV care cascade in Ontario: linkage to care, in care, on antiretroviral treatment, and virally suppressed, 2015, 2015. Available: http://www.ohesi.ca/documents/OHESI-cascade-report17072017-a2.pdf

23 Becker LA, Oxman AD. Overviews of reviews. Cochrane handbook for systematic reviews of interventions Cochrane book series, 2008: 607-31.

24 Mbuagbaw L, Mertz D, Lawson DO, et al. Strategies to improve adherence to antiretroviral therapy and retention in care for people living with HIV in high-income countries: a protocol for an overview of systematic reviews. BMJ Open 2018;8:e022982.

25 Reuters. T. Endnote X7. Philadelphia, PA, USA: Thomson Reuters, 2013.

26 Whiting P, Savović J, Higgins JPT, et al. ROBIS: a new tool to assess risk of bias in systematic reviews was developed. J Clin Epidemiol 2016;69:225-34

27 Tricco AC, Antony J, Vafaei A, et al. Seeking effective interventions to treat complex wounds: an overview of systematic reviews. BMC Med 2015;13:89.

28 Brown P, Brunnhuber K, Chalkidou K, et al. How to formulate research recommendations. BMJ 2006;333:804-6.

29 Lavis JN, Røttingen J-A, Bosch-Capblanch X, et al. Guidance for evidence-informed policies about health systems: linking guidance development to policy development. PLoS Med 2012;9:e1001186.

30 Moher D, Altman DG, Liberati A, et al. PRISMA statement. Epidemiology 2011;22:128.

31 Amankwaa I, Boateng D, Quansah DY, et al. Effectiveness of short message services and voice call interventions for antiretroviral therapy adherence and other outcomes: a systematic review and meta-analysis. PLoS One 2018;13:e0204091.

32 Ambia J, Mandala J. A systematic review of interventions to improve prevention of mother-to-child HIV transmission service delivery and promote retention. $J$ Int AIDS Soc 2016;19:20309.

33 Anglada-Martinez H, Riu-Viladoms G, Martin-Conde M, et al. Does mHealth increase adherence to medication? results of a systematic review. Int J Clin Pract 2015;69:9-32.

34 Arrivillaga M, Martucci V, Hoyos PA, et al. Adherence among children and young people living with HIV/AIDS: a systematic review of medication and comprehensive interventions. Vulnerable Child Youth Stud 2013;8:321-37.

35 Bain-Brickley D, Butler LM, Kennedy GE, et al. Interventions to improve adherence to antiretroviral therapy in children with HIV infection. Cochrane Database Syst Rev 2011;18.

36 Bärnighausen T, Chaiyachati K, Chimbindi N, et al. Interventions to increase antiretroviral adherence in sub-Saharan Africa: a systematic review of evaluation studies. Lancet Infect Dis 2011;11:942-51.

37 Bateganya $\mathrm{MH}$, Amanyeiwe $\mathrm{U}$, Roxo $\mathrm{U}$, et al. Impact of support groups for people living with HIV on clinical outcomes: a systematic review of the literature. J Acquir Immune Defic Syndr 2015;68:74.

38 Bhatta DN, Liabsuetrakul T, McNeil EB. Social and behavioral interventions for improving quality of life of HIV infected people receiving antiretroviral therapy: a systematic review and metaanalysis. Health Qual Life Outcomes 2017;15:80.

39 Binford MC, Kahana SY, Altice FL. A systematic review of antiretroviral adherence interventions for HIV-infected people who use drugs. Curr HIVIAIDS Rep 2012;9:287-312.
40 Brennan A, Browne JP, Horgan M. A systematic review of health service interventions to improve linkage with or retention in HIV care. AIDS Care 2014;26:804-12.

41 Cao B, Gupta S, Wang J, et al. Social media interventions to promote HIV testing, linkage, adherence, and retention: systematic review and meta-analysis. J Med Internet Res 2017;19:e394.

42 Catalani C, Philbrick W, Fraser H, et al. mHealth for HIV Treatment \& Prevention: A Systematic Review of the Literature. Open AIDS J 2013;7:17-41.

43 Chaiyachati $\mathrm{KH}$, Ogbuoji O, Price $\mathrm{M}$, et al. Interventions to improve adherence to antiretroviral therapy: a rapid systematic review. AIDS 2014:28 Suppl 2:S187-204-204.

44 Chang SJ, Choi S, Kim S-A, et al. Intervention strategies based on Information-Motivation-Behavioral skills model for health behavior change: a systematic review. Asian Nurs Res 2014;8:172-81.

45 Charania MR, Marshall KJ, Lyles CM, et al. Identification of evidence-based interventions for promoting HIV medication adherence: findings from a systematic review of U.S.-based studies, 1996-2011. AIDS Behav 2014;18:646-60.

46 Checchi KD, Huybrechts KF, Avorn J, et al. Electronic medication packaging devices and medication adherence: a systematic review. JAMA 2014;312:1237-47.

$47 \mathrm{Cho} \mathrm{H}$, Iribarren S, Schnall R. Technology-Mediated interventions and quality of life for persons living with HIV/AIDS. A systematic review. Appl Clin Inform 2017;8:348-68.

48 Claborn KR, Fernandez A, Wray T, et al. Computer-Based HIV adherence promotion interventions: a systematic review: translation behavioral medicine. Transl Behav Med 2015:5:294306-306.

49 Clay PG, Yuet WC, Moecklinghoff $\mathrm{CH}$, et al. A meta-analysis comparing 48-week treatment outcomes of single and multi-tablet antiretroviral regimens for the treatment of people living with HIV. AIDS Res Ther 2018:15:17.

50 Crepaz N, Baack BN, Higa DH, et al. Effects of integrated interventions on transmission risk and care continuum outcomes in persons living with HIV: meta-analysis, 1996-2014. AIDS 2015;29:2371-83

51 Crepaz N, Tungol-Ashmon MV, Vosburgh HW, et al. Are couplebased interventions more effective than interventions delivered to individuals in promoting HIV protective behaviors? A meta-analysis. AIDS Care 2015;27:1361-6.

52 Daher J, Vijh R, Linthwaite B, et al. Do digital innovations for HIV and sexually transmitted infections work? results from a systematic review (1996-2017). BMJ Open 2017;7:e017604.

53 de Bruin M, Viechtbauer W, Schaalma HP, et al. Standard care impact on effects of highly active antiretroviral therapy adherence interventions: a meta-analysis of randomized controlled trials. Arch Intern Med 2010;170:240-50-50.

54 de Jongh TE, Gurol-Urganci I, Allen E, et al. Integration of antenatal care services with health programmes in low-and middle-income countries: systematic review. J Glob Health 2016;6:010403.

55 de Pee S, Grede N, Mehra D, et al. The enabling effect of food assistance in improving adherence and/or treatment completion for antiretroviral therapy and tuberculosis treatment: a literature review. AIDS Behav 2014;18 Suppl 5:531-41.

56 Decroo T, Rasschaert F, Telfer B, et al. Community-Based antiretroviral therapy programs can overcome barriers to retention of patients and decongest health services in sub-Saharan Africa: a systematic review. Int Health 2013;5:169-79.

57 Demonceau J, Ruppar T, Kristanto P, et al. Identification and assessment of adherence-enhancing interventions in studies assessing medication adherence through electronically compiled drug dosing histories: a systematic literature review and metaanalysis. Drugs 2013;73:545-62.

58 Feyissa GT, Demissie TD. Effect of point of care CD4 cell count tests on retention of patients and rates of antiretroviral therapy initiation in sub-Saharan African countries: a systematic review. JBI Database System Rev Implement Rep 2014;12:395-429.

59 Ford N, Migone C, Calmy A, et al. Benefits and risks of rapid initiation of antiretroviral therapy. AIDS 2018;32:17-23.

60 Ford N, Nachega JB, Engel ME, et al. Directly observed antiretroviral therapy: a systematic review and meta-analysis of randomised clinical trials. Lancet 2009;374:2064-71.

61 Fox MP, Rosen S, Geldsetzer P, et al. Interventions to improve the rate or timing of initiation of antiretroviral therapy for HIV in subSaharan Africa: meta-analyses of effectiveness. J Int AIDS Soc 2016;19:20888

62 Ganguli A, Clewell J, Shillington AC. The impact of patient support programs on adherence, clinical, humanistic, and economic patient outcomes: a targeted systematic review. Patient Prefer Adherence 2016;10:711-25-25. 
63 Gaston GB, Gutierrez SM, Nisanci A. Interventions that retain African Americans in HIV/AIDS treatment: implications for social work practice and research. Soc Work 2015;60:35-42.

64 Geldsetzer P, Yapa HMN, Vaikath M, et al. A systematic review of interventions to improve postpartum retention of women in PMTCT and art care. J Int AIDS Soc 2016;19:20679.

65 Genberg BL, Shangani S, Sabatino K, et al. Improving engagement in the HIV care cascade: a systematic review of interventions involving people living with HIV/AIDS as Peers. AIDS Behav 2016:20:2452-63

66 Govindasamy D, Meghij J, Kebede Negussi E, et al. Interventions to improve or facilitate linkage to or retention in pre-ART (HIV) care and initiation of ART in low- and middle-income settings--a systematic review. J Int AIDS Soc 2014;17:19032.

67 Hart JE, Jeon CY, Ivers LC, et al. Effect of directly observed therapy for highly active antiretroviral therapy on virologic, immunologic, and adherence outcomes: a meta-analysis and systematic review. $J$ Acquir Immune Defic Syndr 2010;54:167-79.

68 Herrmann ES, Matusiewicz AK, Stitzer ML, et al. Contingency management interventions for HIV, tuberculosis, and hepatitis control among individuals with substance use disorders: a Systematized review. J Subst Abuse Treat 2017;72:117-25.

69 Higa DH, Crepaz N, Mullins MM, et al. Identifying best practices for increasing linkage to, retention, and Re-engagement in HIV medical care: findings from a systematic review, 1996-2014. AIDS Behav 2016;20:951-66.

70 Higa DH, Marks G, Crepaz N, et al. Interventions to improve retention in HIV primary care: a systematic review of U.S. studies. Curr HIVIAIDS Rep 2012;9:313-25.

71 Higgs ES, Goldberg AB, Labrique AB, et al. Understanding the role of $\mathrm{mHealth}$ and other media interventions for behavior change to enhance child survival and development in low- and middle-income countries: an evidence review. J Health Commun 2014;19 Suppl 1:164-89.

72 Hill S, Kavookjian J. Motivational interviewing as a behavioral intervention to increase HAART adherence in patients who are HIV-positive: a systematic review of the literature. AIDS Care 2012;24:583-92.

73 Kanters S, Park JJ, Chan K, et al. Use of Peers to improve adherence to antiretroviral therapy: a global network meta-analysis. $J$ Int AIDS Soc 2016;19:21141.

74 Kanters S, Park JJH, Chan K, et al. Interventions to improve adherence to antiretroviral therapy: a systematic review and network meta-analysis. Lancet HIV 2017;4:e31-40.

75 Keane J, Pharr JR, Buttner MP, et al. Interventions to reduce loss to follow-up during all stages of the HIV care continuum in subSaharan Africa: a systematic review. AIDS Behav 2017;21:1745-54.

76 Knight L, Mukumbang FC, Schatz E. Behavioral and cognitive interventions to improve treatment adherence and access to HIV care among older adults in sub-Saharan Africa: an updated systematic review. Syst Rev 2018;7:114.

77 Kredo T, Adeniyi FB, Bateganya M, et al. Task shifting from doctors to non-doctors for initiation and maintenance of antiretroviral therapy. Cochrane Database Syst Rev 2014;17:CD007331.

78 Kredo T, Ford N, Adeniyi FB, et al. Decentralising HIV treatment in lower- and middle-income countries. Cochrane Database Syst Rev 2013;17:CD009987.

79 Lima ICVde, Galvão MTG, Alexandre HdeO, et al. Information and communication technologies for adherence to antiretroviral treatment in adults with HIV/AIDS. Int J Med Inform 2016;92:54$61-61$

$80 \mathrm{Ma}$ PHX, Chan ZCY, Loke AY. Self-Stigma reduction interventions for people living with HIV/AIDS and their families: a systematic review. AIDS Behav 2019;23:707-41.

81 MacPherson P, Munthali C, Ferguson J, et al. Service delivery interventions to improve adolescents' linkage, retention and adherence to antiretroviral therapy and HIV care. Trop Med Int Health 2015;20:1015-32.

82 Manias E, Williams A. Medication adherence in people of culturally and linguistically diverse backgrounds: a meta-analysis. Ann Pharmacother 2010;44:964-82.

83 Mathes T, Pieper D, Antoine S-L, et al. Adherence-enhancing interventions for highly active antiretroviral therapy in HIV-infected patients - a systematic review. HIV Med 2013;14:583-95.

84 Mavegam BO, Pharr JR, Cruz P, et al. Effective interventions to improve young adults' linkage to HIV care in sub-Saharan Africa: a systematic review. AIDS Care 2017;29:1198-204.

85 Mayer JE, Fontelo P. Meta-Analysis on the effect of text message reminders for HIV-related compliance. AIDS Care 2017;29:409-17.

86 Mbeye NM, Adetokunboh O, Negussie E, et al. Shifting tasks from pharmacy to non-pharmacy personnel for providing antiretroviral therapy to people living with HIV: a systematic review and metaanalysis. BMJ Open 2017;7:e015072.

87 Mbuagbaw L, Sivaramalingam B, Navarro T, et al. Interventions for enhancing adherence to antiretroviral therapy (art): a systematic review of high quality studies. AIDS Patient Care STDS 2015;29:248-66.

88 Mbuagbaw L, Ye C, Thabane L. Motivational interviewing for improving outcomes in youth living with HIV. Cochrane Database Syst Rev 2012:9:CD009748.

89 Medley A, Bachanas P, Grillo M, et al. Integrating prevention interventions for people living with HIV into care and treatment programs: a systematic review of the evidence. J Acquir Immune Defic Syndr 2015;68 Suppl 3:S286-96-96.

90 Mills EJ, Lester R, Thorlund K, et al. Interventions to promote adherence to antiretroviral therapy in Africa: a network metaanalysis. Lancet HIV 2014;1:e104-11.

91 Mizuno Y, Higa DH, Leighton CA, et al. Is HIV patient navigation associated with HIV care continuum outcomes? AIDS 2018;32:2557-71.

92 Muessig KE, Nekkanti M, Bauermeister J, et al. A systematic review of recent smartphone, Internet and web 2.0 interventions to address the HIV continuum of care. Curr HIVIAIDS Rep 2015;12:173-90.

93 Murray KR, Dulli LS, Ridgeway K, et al. Improving retention in HIV care among adolescents and adults in low- and middleincome countries: a systematic review of the literature. PLoS One 2017;12:e0184879.

94 Musayón-Oblitas Y, Cárcamo C, Gimbel S. Counseling for improving adherence to antiretroviral treatment: a systematic review. AIDS Care 2019;31:4-13.

95 Mutasa-Apollo T, Ford N, Wiens M, et al. Effect of frequency of clinic visits and medication pick-up on antiretroviral treatment outcomes: a systematic literature review and meta-analysis. J Int AIDS Soc 2017;20:21647.

96 Nachega JB, Adetokunboh O, Uthman OA, et al. CommunityBased interventions to improve and sustain antiretroviral therapy adherence, retention in HIV care and clinical outcomes in low- and middle-income countries for achieving the UNAIDS 90-90-90 targets. Curr HIVIAIDS Rep 2016;13:241-55.

97 Parienti Jean-Jacques, Bangsberg DR, Verdon R, et al. Better adherence with Once-Daily antiretroviral regimens: a Meta-Analysis. Clin Infect Dis 2009;48:488.

98 Park LG, Howie-Esquivel J, Dracup K. A quantitative systematic review of the efficacy of mobile phone interventions to improve medication adherence. J Adv Nurs 2014;70:1932-53.

99 Perazzo J, Reyes D, Webel A. A systematic review of health literacy interventions for people living with HIV. AIDS Behav 2017:21:812-21.

100 Purnomo J, Coote K, Mao L, et al. Using eHealth to engage and retain priority populations in the HIV treatment and care cascade in the Asia-Pacific region: a systematic review of literature. BMC Infect Dis 2018;18:82

101 Quintana Y, Gonzalez Martorell EA, Fahy D, et al. A systematic review on promoting adherence to antiretroviral therapy in HIVinfected patients using mobile phone technology. Appl Clin Inform 2018:9:450-466-66.

102 Ramjan R, Calmy A, Vitoria M, et al. Systematic review and meta-analysis: patient and programme impact of fixeddose combination antiretroviral therapy. Trop Med Int Health 2014;19:501-13

103 Ridgeway K, Dulli LS, Murray KR, et al. Interventions to improve antiretroviral therapy adherence among adolescents in low- and middle-income countries: a systematic review of the literature. PLoS One 2018;13:e0189770.

104 Riley KE, Kalichman S. Mindfulness-based stress reduction for people living with HIV/AIDS: preliminary review of intervention tria methodologies and findings. Health Psychol Rev 2015;9:224-43.

105 Risher KA, Kapoor S, Daramola AM, et al. Challenges in the evaluation of interventions to improve engagement along the HIV care continuum in the United States: a systematic review. AIDS Behav 2017;21:2101-23.

106 Robbins RN, Spector AY, Mellins CA, et al. Optimizing art adherence: update for HIV treatment and prevention. Curr HIVIAIDS Rep 2014;11:423-33.

107 Rocha BS, Silveira MPT, Moraes CG, et al. Pharmaceutical interventions in antiretroviral therapy: systematic review and meta-analysis of randomized clinical trials. J Clin Pharm Ther 2015;40:251-8

108 Rueda S, Park-Wyllie LY, Bayoumi A, et al. Patient support and education for promoting adherence to highly active antiretrovira therapy for HIV/AIDS. Cochrane Database Syst Rev 2006;18. 
109 Ruzagira E, Baisley K, Kamali A, et al. Linkage to HIV care after home-based HIV counselling and testing in sub-Saharan Africa: a systematic review. Trop Med Int Health 2017;22:807-21.

110 Saberi P, Dong BJ, Johnson MO, et al. The impact of HIV clinical pharmacists on HIV treatment outcomes: a systematic review. Patient Prefer Adherence 2012;6:297-322.

111 Saberi P, Johnson MO. Technology-Based self-care methods of improving antiretroviral adherence: a systematic review. PLoS One 2011;6:e27533.

112 Scott-Sheldon LAJ, Carey KB, Johnson BT, et al. Behavioral interventions targeting alcohol use among people living with HIV/AIDS: a systematic review and meta-analysis. AIDS Behav 2017;21:126-43.

113 Sharma M. Evaluating the efficiency of community-based HIV testing and counseling strategies to decrease HIV burden in subSaharan Africa. Dissertation Abstracts International: Section B: The Sciences and Engineering 2017;78.

114 Shaw S, Amico KR. Antiretroviral therapy adherence enhancing interventions for adolescents and young adults 13-24 years of age. JAIDS Journal of Acquired Immune Deficiency Syndromes 2016;72:387-99.

115 Suthar AB, Nagata JM, Nsanzimana S, et al. Performance-Based financing for improving HIV/AIDS service delivery: a systematic review. BMC Health Serv Res 2017;17:6.

116 Swann M. Economic strengthening for retention in HIV care and adherence to antiretroviral therapy: a review of the evidence. AIDS Care 2018;30:99-125.

117 Tang AM, Quick T, Chung M, et al. Nutrition assessment, counseling, and support interventions to improve health-related outcomes in people living with HIV/AIDS: a systematic review of the literature. J Acquir Immune Defic Syndr 2015;68 Suppl 3:S340-9.

118 Van Camp YP, Van Rompaey B, Elseviers MM. Nurse-Led interventions to enhance adherence to chronic medication: systematic review and meta-analysis of randomised controlled trials. Eur J Clin Pharmacol 2013;69:761-70.

119 van der Heijden I, Abrahams N, Sinclair D, et al. Psychosocial group interventions to improve psychological well-being in adults living with HIV. Cochrane Database of Systematic Reviews 2017;68.

120 van Velthoven MHMMT, Brusamento S, Majeed A, et al. Scope and effectiveness of mobile phone messaging for HIV/AIDS care: a systematic review. Psychol Health Med 2013;18:182-202-202.

121 van Velthoven MHMMT, Tudor Car L, Car J, et al. Telephone consultation for improving health of people living with or at risk of HIV: a systematic review. PLoS One 2012;7:e36105.
122 Vervloet M, Linn AJ, van Weert JCM, et al. The effectiveness of interventions using electronic reminders to improve adherence to chronic medication: a systematic review of the literature. J Am Med Inform Assoc 2012;19:696-704.

123 Vojnov L, Markby J, Boeke C, et al. Poc CD4 testing improves linkage to HIV care and timeliness of art initiation in a public health approach: a systematic review and meta-analysis. PLoS One 2016;11:e0155256

124 Wise J, Operario D. Use of electronic reminder devices to improve adherence to antiretroviral therapy: a systematic review. AIDS Patient Care STDS 2008;22:495-504.

125 Wouters E, Van Damme W, van Rensburg D, et al. Impact of community-based support services on antiretroviral treatment programme delivery and outcomes in resource-limited countries: a synthetic review. BMC Health Serv Res 2012;12:194.

126 Wynberg E, Cooke G, Shroufi A, et al. Impact of point-of-care CD4 testing on linkage to HIV care: a systematic review. J Int AIDS Soc 2014;17:18809.

127 Yang Y. State of the science: the efficacy of a multicomponent intervention for art adherence among people living with HIV. Journal of the Association of Nurses in AIDS Care 2014;25:297-308.

128 Young T, Busgeeth K. Home-Based care for reducing morbidity and mortality in people infected with HIV/AIDS. Cochrane Database Syst Rev 2010;13:CD005417.

$129 \mathrm{Ng} \mathrm{M}$, Gakidou E, Levin-Rector A, et al. Assessment of populationlevel effect of Avahan, an HIV-prevention initiative in India. The Lancet 2011;378:1643-52.

130 Haberer JE, Sabin L, Amico KR, et al. Improving antiretroviral therapy adherence in resource-limited settings at scale: a discussion of interventions and recommendations. J Int AIDS Soc 2017;20:21371.

131 World Health Organization. Progress report 2016: prevent HIV test and treat all: who support for country impact: World Health organization 2016.

132 Geng EH, Odeny TA, Lyamuya R, et al. Retention in care and patient-reported reasons for undocumented transfer or stopping care among HIV-infected patients on antiretroviral therapy in eastern Africa: application of a sampling-based approach. Clin Infect Dis 2016;62:935-44.

133 Mugavero MJ, Westfall AO, Zinski A, et al. Measuring retention in HIV care: the elusive gold standard. J Acquir Immune Defic Syndr 2012;61:574-80-80. 